\title{
Perinatal Outcome in Women with Hypertensive Disorders of Pregnancy: A Retrospective Cohort Study
}

\author{
Gezehagn Endeshaw ${ }^{1}$ and Yifru Berhan ${ }^{2}$ \\ ${ }^{1}$ Hawassa University, 1560 Hawassa, Ethiopia \\ ${ }^{2}$ Hawassa University College of Medicine and Health Sciences, 1560 Hawassa, Ethiopia \\ Correspondence should be addressed to Yifru Berhan; yifrub@yahoo.com
}

Received 11 August 2014; Accepted 23 December 2014

Academic Editor: Guido Iaccarino

Copyright (c) 2015 G. Endeshaw and Y. Berhan. This is an open access article distributed under the Creative Commons Attribution License, which permits unrestricted use, distribution, and reproduction in any medium, provided the original work is properly cited.

\begin{abstract}
Background. Hypertensive disorders of pregnancy (HDP) are multisystem diseases known to increase the risk of perinatal mortality worldwide, with a significant proportion of these deaths occurring in low income countries. However, little is known about the obstetric and treatment predictors of perinatal mortality in women with HDP. Methods. A retrospective cohort study design was used to include 1015 hypertensive pregnant women who gave birth to 1110 babies between 2008 and 2013 in three university teaching hospitals. Bivariate and multivariate regression models were used to estimate the associations between selected predictor variables and perinatal mortality taking the onset of HDP illness to death or discharge from the hospital as the time period. Results. There were 322 perinatal deaths resulting in a perinatal mortality rate (PMR) of 290/1000 total births. The proportion of stillbirths was more than 4 -fold higher than early neonatal deaths ( $81 \%$ versus $19 \%)$. The multivariate analysis demonstrated that multiparity (OR, 1.6; 95\% CI, 1.12-228), grand multiparity (OR, 2.8; 95\% CI, 1.55-4.92), preterm (OR, 1.5; 95\% CI, 1.02-2.35) and very preterm gestational age (OR, 7.7; 95\% CI, 5.26-11.20), lack of antenatal care (OR, 2.0; 95\% CI, 1.43-2.67), having eclampsia (OR, 4.1; 95\% CI, 2.85-6.04), antepartum or before (OR, 6.6; 95\% CI, 3.40-12.75) and intrapartum onset of HDP (OR, 4.0; 95\% CI, 1.99-8.04), raised SGOT level (OR, 2.3; 95\% CI, 1.30-3.91), vaginal delivery (OR, 5.3; 95\% CI, 2.93-9.54), low fetal birth weight (OR, 4.3; 95\% $\mathrm{CI}, 2.56-7.23)$, and maternal death (OR, 12.8; 95\% CI, 2.99-54.49) were independent predictors of perinatal mortality. Conclusion. This study showed that the PMR of HDP was among the highest in the world. Parity, gestational age, type and onset of HDP, mode of delivery, birthweight, and maternal outcome were strong predictors of perinatal mortality.
\end{abstract}

\section{Introduction}

Hypertensive disorders of pregnancy (HDP) are multisystem diseases, which include chronic (preexisting) hypertension, gestational hypertension, preeclampsia, eclampsia, and preeclampsia superimposed on chronic hypertension [1]. These disorders may complicate $5 \%-10 \%$ of all pregnancies [2] and are leading causes of maternal and perinatal mortality and morbidity worldwide [3].

The high perinatal mortality in women with HDP is mainly due to premature delivery and growth restriction [4, 5]. A secondary analysis from the World Health Organization (WHO) multicountry survey has shown that there were about 3 - and 5-fold increased risk of perinatal death in women with preeclampsia and eclampsia, respectively, as compared to women with no preeclampsia/eclampsia [3]. Specifically, the perinatal mortality in women with hypertensive disorders was reported as 230/1000 births from Pakistan [6], 144/1000 births from Turkey [7], 165/1000 births from Addis Ababa [8], and 317/1000 births from Jimma/Ethiopia [9]. Another study, which included only eclamptic mothers, also showed the high perinatal mortality [10].

Although there is a large body of literature that described the magnitude and associated complications of HDP, little is done to assess the predictors of perinatal mortality, particularly in low and middle income countries [11-13]. This is despite the fact that the majority of perinatal deaths due to complications of HDP have occurred in the low and middle income countries [6-10,14]. Similarly, the authors of this study could not find a published study on HDP in 
the Southern Regional State of Ethiopia. Furthermore, the authors observed high perinatal mortality in the hospitals where they have been working. This study was planned with an objective of determining the predictors of perinatal mortality among women with HDP.

\section{Methods}

2.1. Study Setting and Design. This analysis was done using data from three university teaching hospitals in the Southern Regional State of Ethiopia (Hawassa Referral Hospital, Hosanna Hospital, and Yirgalem Hospital) from 2008 to 2013. During this period, a total of 30,750 babies were delivered after 28 weeks of gestational age, of which 1098 women were diagnosed to have HDP. A retrospective cohort study design was used to include the patient's data from the onset of HDP to the time end of treatment was declared (mother discharged as a cure or for death). This study included all eligible women with HDP admitted to the study hospitals during the study period. The exclusion criteria were baby delivery before 28 weeks of gestation, lost or incomplete data, or mother death on arrival.

2.2. Variables and Data Collection. An association of perinatal mortality was assessed for maternal age, parity, gestational age, antenatal care, number of fetuses, type of HDP, onset of HDP, severity symptoms of HDP, proteinuria, hemoglobin, platelet count, creatinine, serum oxaloacetic transaminase (SGOT) level, labor onset, type of anticonvulsant or antihypertensive given, mode of delivery, fetal birth weight, and maternal outcome.

For each study hospital, nine nurse data collectors were recruited and trained. To access the detailed data in the patient chart, the delivery log book was used as an entry point to identify the HDP patients by their card number. A structured data collecting format was prepared and used to abstract relevant data from the included patients' charts starting from the onset of signs and symptoms of HDP to the time end date was declared.

2.3. Data Processing and Analysis. After completeness was checked, data were coded, entered, and analyzed using computer data analysis software program (SPSS version 20). Bivariate and multivariate regression models were used to estimate the associations between selected predictor variables and perinatal mortality. A statistically significant association was considered when the odds ratio (OR) 95\% confidence interval did not include the number 1 . Variables which did not show statistical significance in the univariate analysis were excluded from the multivariate analysis.

2.4. Operational Definitions. The finding of raising blood pressure or severe symptoms of hypertension with significant proteinuria was enough to diagnose preeclampsia. The occurrence of convulsion or coma not attributable to other causes defined eclampsia. Chronic hypertension was diagnosed when the women were found to have hypertension before the occurrence of pregnancy or before 20 weeks of gestation. A new onset or worsening of proteinuria and/or worsening of hypertension in women with a known chronic hypertension defined superimposed preeclampsia. The development of an elevated blood pressure during the second half of pregnancy without proteinuria and without severity symptoms was used to diagnose gestational hypertension $[1,3,5]$.

In this study, other HDP included all women with chronic hypertension, gestational hypertension, and superimposed preeclampsia. Pregnant or postpartum women with a systolic blood pressure $(\mathrm{BP})<140 \mathrm{mmHg}$ and diastolic $\mathrm{BP}<$ $90 \mathrm{mmHg}$ were categorized as normotensive. A systolic BP $\geq$ $140 \mathrm{mmHg}$ and diastolic BP $\geq 90 \mathrm{mmHg}$ measured twice six hours apart defined mild to moderate hypertension. A single record of systolic $\mathrm{BP} \geq 160 \mathrm{mmHg}$ and diastolic $\mathrm{BP} \geq$ $110 \mathrm{mmHg}$ was enough to define severe hypertension. Headache, blurred vision, epigastric pain, and vomiting were taken as severity symptoms of HDP.

Significant proteinuria was considered when the qualitative test revealed +2 and above or +1 if the specific gravity was $<1.020$. Creatinine level $<1$ and $1+\mathrm{mg} / \mathrm{dL}$ and SGOT level raised by $<$ or $>2$-fold from the baseline were included in the analysis as a proxy indicator for status of renal function and liver function, respectively. The normal value of SGOT level was $<36$ IU/L in all study hospitals. Platelet count was also dichotomized as $<$ or $>100,000 / \mathrm{mm}^{3}$. Degree of anemia was categorized as severe to moderate $(<10 \mathrm{gm} / \mathrm{dL})$, mild (10$11.9 \mathrm{gm} / \mathrm{dL})$, and no anemia $(12+\mathrm{gm} / \mathrm{dL})$.

All fetal deaths in utero (stillbirth) and all early neonatal deaths (deaths that occurred in the first week of neonatal life before discharge from the study hospital) after 28 weeks of gestation were included in the perinatal mortality. The perinatal mortality rate (PMR) was determined out of 1000 total births among women included in this study.

2.5. Ethical Consideration. Ethical clearance was obtained from institutional review board of Hawassa University College of Medicine and Health Sciences. Since the study was retrospective by design, written consent from patients was not required. Anonymity was secured by analyzing and presenting the data in aggregate.

\section{Results}

This study included 1015 hypertensive pregnant women who gave birth to 1110 babies (95 sets of twins) after 28 weeks of gestational age. The detailed description is presented in a separate analysis. Pertinent to this analysis, there were 322 perinatal deaths resulting in a perinatal mortality rate of 290/1000 total births. The proportion of stillbirths was more than 4-fold higher than early neonatal deaths: 261 (81\%) stillbirths versus 61 (18.9\%) early neonatal deaths. Twin accounted for 46 (14.3\%) of the total perinatal deaths.

The distribution of perinatal mortality by type of HDP was preeclampsia 159 (49.4\%), eclampsia 143 (44.4), and other types of HDP 20 (6.2\%). However, the case fatality rate of preeclampsia $(24 \%)$ was significantly lower than eclampsia (38.2\%) and other types of HDP (33.3\%). The majority of perinatal deaths $(261 / 322,81 \%)$ occurred among women with antepartum onset of HDP. Nearly two-thirds of the perinatal deaths were either very preterm or preterm $(201 / 322,62 \%)$. 
Among the total perinatal deaths in antepartum period, $71 \%$ $(184 / 261)$ were either very preterm or preterm. In intrapartum and antepartum onset of HDP, the proportion of perinatal deaths before term was about $39 \%$. The premature perinatal deaths were more pronounced in preeclamptic than in eclamptic women (31\% versus 61\%).

The median gestational ages for perinatal deaths and survivors in women with preeclampsia were 32 and 38 weeks, respectively. In eclamptic women, however, the median gestational ages for perinatal deaths and survivors were term (37 versus 38 weeks). Similarly, the median birth weight of perinatal deaths of preeclamptic mothers was nearly 2fold lower than the survivors ( $1.5 \mathrm{~kg}$ versus $2.7 \mathrm{~kg}$ ). Among eclamptic women, the median birth weight of perinatal deaths was relatively close to the survivors (2.3 versus $2.7 \mathrm{~kg}$ ). Overall, nearly three-fourths of babies who died in the perinatal period were having birth weight below $2.5 \mathrm{~kg}$ (233/322, $72 \%)$. In the majority of perinatal deaths, their mothers' hemoglobin level $(197 / 322,61 \%)$, platelet count (216/322, $67 \%)$, and SGOT level $(169 / 322,52 \%)$ were in the normal range.

Table 1 shows the logistic regression of the selected variables as potential determinants for perinatal mortality. In the bivariate analysis, perinatal mortality was found to be weakly associated with multiparty (crude OR, 1.4; 95\% CI, 1.04-1.80) and strongly associated with grand multiparity (COR, 2.3; 95\% CI, 1.44-3.68). Other variables, which have shown strong association with perinatal mortality, were very preterm delivery (COR, 8.1; 95\% CI, 5.82-11.22), lack of antenatal care follow-up (COR, 2.3; 95\% CI, 1.75-2.97), having eclampsia (COR, 2.0; 95\% CI, 1.52-2.63), antepartum onset of HDP (COR, 2.6; 95\% CI, 1.57-4.38), and the highest diastolic blood pressure (BP) being <90 mmHg (COR, 2.1; 95\% CI, 1.11-4.00). There was also a statistically significant association of perinatal mortality with the highest systolic $\mathrm{BP} \geq 160 \mathrm{mmHg}$ (COR, 1.5; 95\% CI, 1.07-1.99) and highest diastolic $\mathrm{BP} \geq 110 \mathrm{mmHg}$ (COR, 1.7; 95\% CI, 1.33-2.31).

In the multivariate analysis, the perinatal mortality has increased by about 1.6- and 2.8-fold among multiparous and grand multiparous women, respectively. The risk of perinatal mortality in very preterm babies was 7.7-fold higher than term babies. Lack of antenatal care and having eclampsia increased the risk of perinatal mortality by more than 2and 4-fold. Antepartum and intrapartum onset of HDP also independently predicted the chance of perinatal mortality by 6.6- and 4-fold as compared to postpartum onset of HDP.

In Table 2, the association of perinatal mortality with selected laboratory findings, treatment modalities, and the outcome is presented. Among selected laboratory tests, the bivariate analysis has demonstrated significant association of perinatal mortality with the lowest platelet count of $<100,000 / \mathrm{mm}^{3}$ (COR, 2.3; 95\% CI, 1.66-3.31), highest creatinine level of $\geq 1 \mathrm{mg} / \mathrm{dL}$ (COR, 1.5; 95\% CI, 1.05-2.03), and highest SGOT raised by $\geq 2$-fold from the normal level (COR, 2.9; 95\% CI, 1.96-4.22).

Perinatal mortality was higher among women whose labor was either spontaneously initiated (COR, 2.3; 95\% CI, 1.49-3.78) or induced (COR, 4.9; 95\% CI, 3.16-7.49). There was also a strong association of perinatal mortality with vaginal delivery (COR, 4.5; 95\% CI, 3.32-6.13). Birth weight $<2.5 \mathrm{~kg}$ was associated with four times increased risk of mortality during the perinatal period (COR, 4.1; 95\% CI, 3.025.45). The odds of perinatal mortality among mothers who lost their life were more than 7-fold higher than alive mothers (COR, 7.1; 95\% CI, 3.79-13.38). In the multivariate analysis, however, a strong association of perinatal mortality with highest SGOT raised by $\geq 2$-fold (OR, 2.3), vaginal delivery (OR, 5.3), low birth weight (OR, 4.3), and maternal death (OR, 12.8) was demonstrated.

As shown in Table 3, a multivariate analysis was done by disaggregating the perinatal mortality into stillbirth and early neonatal mortality (ENM). The independent predictors of stillbirth include multiparity $(\mathrm{OR}, 1.6)$, grand multiparity $(\mathrm{OR}, 2.6)$, very preterm gestational age (OR, 6.5), lack of antenatal care (OR, 2.1), developing eclampsia (OR, 4.1), and antepartum $(\mathrm{OR}, 7.8)$ or intrapartum $(\mathrm{OR}, 5.0)$ onset of HDP. Among the laboratory findings, lowest platelet count < $100,000 / \mathrm{mm}^{3}$ (OR, 2.2) and SGOT level raised by $\geq 2$-fold (OR, 2.2) were independently associated with stillbirths. There was also a strong association of stillbirth with vaginal delivery (OR, 7.1), birth weight $<2.5 \mathrm{~kg}$ (OR, 4.0), and maternal death $(\mathrm{OR}, 10.4)$.

On the other hand, the independent predictors of ENM were very preterm gestational age $(\mathrm{OR}, 3.6)$, having eclampsia (OR, 2.9), vaginal delivery (OR, 4.1), birth weight $<2.5 \mathrm{~kg}$ (OR, 6.2), and maternal death (OR, 11.7). Otherwise, the statistically significant association of perinatal mortality, stillbirth, and ENM was not observed with maternal age, number of fetuses, HDP severity symptoms, significant proteinuria, hemoglobin level, and type of anticonvulsant or antihypertensive given.

\section{Discussion}

Consistent with previous studies' findings [3, 7, 15-17], this study has shown a high perinatal mortality among women with HDP. However, the PMR in this study (290/1000 births) was lower than the report from Jimma/Ethiopia [9] but higher than the reports from Pakistan [6], Turkey [7], and Addis Ababa [8].

Specific to the objective of this study, the analysis demonstrated that the independent predictor variables of perinatal mortality were parity, gestational age, antenatal care, type and onset of HDP, SGOT level, mode of delivery, fetal birth weight, and maternal outcome. An increase in the risk of perinatal mortality with an increase in parity was observed in this study. A separate analysis has also shown the increase in maternal mortality with an increase in parity [18]. This is despite the fact that HDP commonly occur among primigravida women $[15,19]$.

The significantly increased risk of perinatal mortality among babies with low gestational age and low birth weight in this study is consistent with several other studies $[4,5,20,21]$. The finding of a strong association of perinatal mortality with low gestational age and low birth weight is probably in line with the increased risk of perinatal mortality among babies with antepartum onset of HDP. It was observed that 
TABLE 1: Predictors of perinatal mortality among women with hypertensive disorders of pregnancy (HDP), Ethiopia, 2008-2013.

\begin{tabular}{|c|c|c|c|c|}
\hline Variables $^{*}$ & Total & Perinatal deaths (\%) & Crude OR $(95 \%$ CI $)$ & Adjusted OR (95\% CI) \\
\hline \multicolumn{5}{|l|}{ Maternal age (years) } \\
\hline $15-19$ & 57 & 31.6 & $1.0(0.59-1.85)$ & \\
\hline $20-34$ & 876 & 31.3 & 1 & \\
\hline $35-49$ & 82 & 36.6 & $1.2(0.79-1.98)$ & \\
\hline \multicolumn{5}{|l|}{ Parity } \\
\hline Primigravida & 536 & 27.4 & 1 & 1 \\
\hline Multipara (I-IV) & 400 & 34.5 & $1.4(1.04-1.80)^{¥}$ & $1.6(1.12-2.228)^{\ddagger}$ \\
\hline Grand multipara $(\mathrm{V}+)$ & 79 & 46.8 & $2.3(1.44-3.68)^{\ddagger}$ & $2.8(1.55-4.92)^{\ddagger}$ \\
\hline \multicolumn{5}{|l|}{ Gestational age (weeks) } \\
\hline Very preterm $(<34)$ & 240 & 63.8 & $8.1(5.82-11.22)^{\dagger}$ & $7.7(5.26-11.20)^{\dagger}$ \\
\hline Preterm (34-36) & 193 & 24.9 & $1.5(1.04-2.23)^{¥}$ & $1.5(1.02-2.35)^{¥}$ \\
\hline Term $+(\geq 37)$ & 677 & 17.9 & 1 & 1 \\
\hline \multicolumn{5}{|l|}{ Number of fetuses } \\
\hline Singleton & 920 & 30.0 & 1 & \\
\hline Twin & 190 & 24.2 & $0.7(0.52-1.07)$ & \\
\hline \multicolumn{5}{|l|}{ Antenatal care } \\
\hline Yes & 633 & 22.7 & 1 & 1 \\
\hline No & 382 & 40.0 & $2.3(1.75-2.97)^{\dagger}$ & $2.0(1.43-2.67)^{\dagger}$ \\
\hline \multicolumn{5}{|l|}{ Type of HDP } \\
\hline Preeclampsia & 612 & 26.0 & 1 & 1 \\
\hline Eclampsia & 346 & 41.3 & $2.0(1.52-2.63)^{\dagger}$ & $4.1(2.85-6.04)^{\dagger}$ \\
\hline Other HDP & 57 & 35.1 & $1.6(0.92-2.86)$ & $1.3(0.65-2.49)$ \\
\hline \multicolumn{5}{|l|}{ Onset of HDP } \\
\hline Antepartum or before & 721 & 36.2 & $2.6(1.57-4.38)^{\dagger}$ & $6.6(3.40-12.75)^{\dagger}$ \\
\hline Intrapartum & 183 & 22.9 & $1.4(0.77-2.55)$ & $4.0(1.99-8.04)^{\dagger}$ \\
\hline Postpartum & 111 & 17.1 & 1 & 1 \\
\hline \multicolumn{5}{|l|}{ HDP severity symptoms } \\
\hline Yes (one or more) & 847 & 32.8 & $1.3(0.92-1.92)$ & \\
\hline None & 168 & 26.2 & 1 & \\
\hline \multicolumn{5}{|l|}{ Highest systolic BP } \\
\hline$<140 \mathrm{mmHg}$ & 60 & 36.7 & $1.5(0.86-2.70)$ & $1.0(0.44-2.24)$ \\
\hline $140-159$ & 270 & 25.9 & 1 & 1 \\
\hline $160+$ & 685 & 33.6 & $1.5(1.07-1.99)^{¥}$ & $1.0(0.67-1.55)$ \\
\hline \multicolumn{5}{|l|}{ Highest diastolic BP } \\
\hline$<90 \mathrm{mmHg}$ & 39 & 43.6 & $2.1(1.11-4.00)^{¥}$ & $2.3(0.88-5.79)$ \\
\hline $90-109$ & 425 & 24.5 & 1 & 1 \\
\hline $110+$ & 551 & 36.5 & $1.7(1.33-2.31)^{\dagger}$ & $1.4(0.96-2.03)$ \\
\hline
\end{tabular}

${ }^{¥} P<0.05 ;{ }^{*} P \leq 0.001 ;{ }^{\dagger} P<0.0001$. BP: blood pressure. ${ }^{*}$ All variables describe the mother's condition except gestational age and fetuses number. ${ }^{* *}$ Adjusted for parity, gestational age, antenatal care, type of HDP, onset of HDP, highest systolic BP, and highest diastolic BP.

nearly three-fourths of the perinatal deaths (71\%) in women with antepartum onset of HDP were either preterm or very preterm at birth. The implication is that HDP has probably exposed several babies to premature delivery and its complications. Previous study also reported the increased risk of premature delivery in women with HDP [22]. Furthermore, other studies focusing only on eclamptic women reported that perinatal deaths were caused by prematurity in $68 \%$ [20] and $43 \%$ [21].

On the other hand, significantly increased odds of perinatal mortality were observed among women with eclampsia, which was consistent with other studies $[15,23]$. This is probably because of the severe nature of the eclampsia disease, which usually complicates by severe intrauterine asphyxia, severe placental abruption, and neonatal sepsis [24]. However, the proportion of premature perinatal mortality was about 2-fold higher in women with preeclampsia than women with eclampsia. This finding might be due to the fact that in the majority of the cases preeclampsia is the initial disease before eclampsia, which may be the reason to come to the hospital earlier than women with eclampsia and get the pregnancy terminated. This study has also shown that preterm delivery rate was nearly twice higher in preeclamptic than in eclamptic women. 
TABLE 2: Association of perinatal mortality with selected laboratory findings, treatment modalities, and outcome among women with hypertensive disorders of pregnancy, Ethiopia, 2008-2013.

\begin{tabular}{|c|c|c|c|c|}
\hline Variables ${ }^{*}$ & Total & Perinatal deaths (\%) & Crude HR (95\% CI) & $\begin{array}{c}\text { Adjusted }{ }^{* *} \\
\text { HR }(95 \% \text { CI })\end{array}$ \\
\hline \multicolumn{5}{|c|}{ Hemoglobin level (gm/dL) } \\
\hline$<10.0$ & 158 & 36.1 & $1.0(0.71-1.51)$ & \\
\hline $10-11.9$ & 255 & 26.7 & $0.7(0.51-1.00)$ & \\
\hline$\geq 12$ & 602 & 32.7 & 1 & \\
\hline \multicolumn{5}{|l|}{ Platelet count in $\mathrm{mm} 3$} \\
\hline$<100$ & 223 & 47.5 & $2.3(1.66-3.31)^{\dagger}$ & $1.5(0.83-2.85)$ \\
\hline$\geq 100$ & 792 & 27.3 & 1 & 1 \\
\hline \multicolumn{5}{|c|}{ Proteinuria (qualitative) } \\
\hline Insignificant & 266 & 27.1 & 1 & \\
\hline Significant & 749 & 30.4 & $1.2(0.89-1.68)$ & \\
\hline \multicolumn{5}{|c|}{ Highest creatinine (gm/dL) } \\
\hline$<1.0$ & 494 & 26.3 & 1 & 1 \\
\hline $1.0+$ & 521 & 36.8 & $1.5(1.05-2.03)^{¥}$ & $0.8(0.51-1.39)$ \\
\hline \multicolumn{5}{|c|}{ Highest SGOT (IU/microl) } \\
\hline$<2$-fold raise & 689 & 24.5 & 1 & 1 \\
\hline$\geq 2$-fold raise & 326 & 46.9 & $2.9(1.96-4.22)^{\dagger}$ & $2.3(1.30-3.91)^{\ddagger}$ \\
\hline \multicolumn{5}{|c|}{ Antihypertensive drug given } \\
\hline Yes & 811 & 32.8 & 1 & \\
\hline No & 204 & 27.5 & $0.8(0.55-1.11)$ & \\
\hline \multicolumn{5}{|c|}{ Anticonvulsant drug given } \\
\hline $\mathrm{MgSO}_{4}$ & 641 & 30.6 & 1 & \\
\hline Diazepam & 374 & 33.7 & $1.1(0.81-1.41)$ & \\
\hline \multicolumn{5}{|l|}{ Labor onset } \\
\hline Spontaneous & 331 & 26.3 & $2.3(1.49-3.78)^{\dagger}$ & $0.7(0.25-2.07)$ \\
\hline Induced & 504 & 41.1 & $4.9(3.16-7.49)^{\dagger}$ & $1.6(0.69-3.81)$ \\
\hline Direct C/S & 180 & 15.6 & 1 & 1 \\
\hline \multicolumn{5}{|l|}{ Mode of delivery } \\
\hline Vaginal & 625 & 41.1 & $4.5(3.32-6.13)^{\dagger}$ & $5.3(2.93-9.54)^{\dagger}$ \\
\hline Caesarean section & 485 & 13.4 & 1 & 1 \\
\hline \multicolumn{5}{|l|}{ Birth weight (kg) } \\
\hline$<2.5$ & 545 & 42.7 & $4.1(3.02-5.45)^{\dagger}$ & $4.3(2.56-7.23)^{\dagger}$ \\
\hline $2.5+$ & 565 & 15.7 & 1 & 1 \\
\hline \multicolumn{5}{|l|}{ Maternal outcome } \\
\hline Alive on discharge & 964 & 29.0 & 1 & 1 \\
\hline Dead & 51 & 82.3 & $7.1(3.79-13.38)^{\dagger}$ & $12.8(2.99-54.49)^{\ddagger}$ \\
\hline
\end{tabular}

${ }^{¥} P<0.05 ;{ }^{\ddagger} P=0.001 ;{ }^{\dagger} P<0.0001 .{ }^{*}$ All variables describe the mother’s condition except mode of delivery and birth weight. ${ }^{* *}$ Adjusted for platelet count, creatinine level, SGOT level, labor onset, mode of delivery, birth weight, and maternal outcome. C/S: Caesarean section. SGOT: serum glutamic oxaloacetic transaminase.

This study has also shown the independent association of perinatal mortality with lack of antenatal care, which is probably an indirect evidence of delay in recognition and intervention in the affected mothers. This is because the delay in diagnosis and delay in providing treatment in the early stage of the disease are likely to progress to severe stage of the disease like eclampsia, which was in turn found to have a strong association with perinatal mortality. Previous studies also reported reduction in perinatal mortality among hypertensive women who had antenatal care $[25,26]$.

Among the selected laboratory tests to assess the severity of HDP, only SGOT level $\geq 2$-fold raise from the normal range was an independent predictor of perinatal mortality. The platelet count and creatinine levels were predictors of perinatal mortality in the unadjusted analysis, but hemoglobin was not. This is probably because the intrauterine wellbeing of 
TABLE 3: Multivariate analysis of stillbirth and early neonatal mortality predictors in women with hypertensive disorders of pregnancy, Ethiopia, 2008-2013.

\begin{tabular}{|c|c|c|}
\hline Variable & $\begin{array}{c}\text { Stillbirths } \\
\text { Adjusted OR (95\% CI) }\end{array}$ & $\begin{array}{l}\text { Early neonatal deaths } \\
\text { Adjusted OR ( } 95 \% \text { CI) }\end{array}$ \\
\hline \multicolumn{3}{|l|}{ Parity } \\
\hline Primipara & 1 & \\
\hline Multipara & $1.6(1.09-2.33)^{¥}$ & \\
\hline Grand multipara & $2.5(1.34-4.71)^{\ddagger}$ & \\
\hline \multicolumn{3}{|l|}{ Gestational age (weeks) } \\
\hline Very preterm $(<34)$ & $6.5(4.33-9.85)^{\dagger}$ & $3.6(1.49-8.76)^{\dagger}$ \\
\hline Preterm (34-36) & $1.4(0.87-2.27)$ & $0.7(0.23-2.28)$ \\
\hline Term $+(\geq 37)$ & 1 & 1 \\
\hline \multicolumn{3}{|l|}{ Antenatal care } \\
\hline Yes & 1 & \\
\hline No & $2.1(1.47-2.93)^{\dagger}$ & \\
\hline \multicolumn{3}{|l|}{ Type of HDP } \\
\hline Preeclampsia & 1 & 1 \\
\hline Eclampsia & $4.1(2.69-6.09)^{\dagger}$ & $2.9(1.37-6.17)^{\ddagger}$ \\
\hline Other HDP & $1.5(0.77-3.09)$ & $0.8(0.13-4.42)$ \\
\hline \multicolumn{3}{|l|}{ Onset of HDP } \\
\hline Antepartum or before & $7.8(3.59-16.86)^{\dagger}$ & \\
\hline Intrapartum & $5.0(2.20-11.20)^{\dagger}$ & \\
\hline Postpartum & 1 & \\
\hline \multicolumn{3}{|c|}{ Lowest platelet count per $\mathrm{mm} 3$} \\
\hline$<100,000$ & 1 & \\
\hline $100,000+$ & $2.2(1.14-4.13)^{¥}$ & \\
\hline \multicolumn{3}{|l|}{ Highest SGOT (IU/microl) } \\
\hline$<2$-fold raise & 1 & \\
\hline$\geq 2$-fold raise & $2.2(1.21-3.89)^{¥}$ & \\
\hline \multicolumn{3}{|l|}{ Mode of delivery } \\
\hline Vaginal & $7.1(3.48-14.39)^{\dagger}$ & $4.1(1.81-9.45)^{\dagger}$ \\
\hline Caesarean section & 1 & 1 \\
\hline \multicolumn{3}{|l|}{ Birth weight $(\mathrm{kg})$} \\
\hline$<2.5$ & $4.0(2.24-7.04)^{\dagger}$ & $6.2(2.31-16.57)^{\dagger}$ \\
\hline $2.5+$ & 1 & 1 \\
\hline \multicolumn{3}{|l|}{ Maternal condition } \\
\hline Alive on discharge & 1 & 1 \\
\hline Dead & $10.4(2.15-50.83)^{\dagger}$ & $11.7(3.01-45.66)^{\dagger}$ \\
\hline
\end{tabular}

${ }^{¥} P<0.05 ;{ }^{\ddagger} P=0.001 ;{ }^{\dagger} P<0.0001$.

the fetus is mainly dependent on the adequacy of uteroplacental blood flow and placental function [27], which may not be much influenced by the maternal renal and hematologic function derangements. Previous study, however, reported an increase in the risk of perinatal mortality in women with proteinuria [28]. The implication is that the association of maternal organs function derangements due to HDP needs further investigation.

Similarly, this study did not show statistically significant association of perinatal mortality with a type of anticonvulsant in both bivariate and multivariate analyses. One previous study also reported that there was no difference in perinatal mortality between the diazepam and magnesium sulphate groups [29]. Another study, however, reported nearly 3fold reduction in perinatal mortality among magnesium sulphate group [30]. It was also noted that magnesium sulphate is superior to diazepam in preventing and controlling convulsion in women with HDP [31-33], which is indirectly preventing the most perinatal deadly complication (eclampsia). Nevertheless, the inconsistent findings of the effect of magnesium sulphate on perinatal mortality invoke meta-analysis.

The strong association of perinatal mortality with vaginal delivery may not necessarily show the increased risk of perinatal mortality among babies delivered via the vaginal route. This is because $80 \%$ of the stillbirths occurred before 
the onset of labor or before caesarean delivery was considered. Otherwise, caesarean delivery is known to result in expeditious delivery and probably has reduced the risk HDP related complications and perinatal mortality.

The very strong association of perinatal mortality with maternal mortality may strengthen the finding of significant association of perinatal mortality with eclampsia, which was an identified risk factor for both perinatal and maternal deaths as this study and previous studies showed $[18,20,21$, 34-36].

This study has several limitations. Since the study was retrospective by design, we could not get some data on social and service related factors. In other words, the quality of neonatal care was not assessed, which has probably contributed to high neonatal mortality among preterm and/or asphyxiated babies. Similarly, due to lack of documented data, the measurements for antepartum and postpartum care were not comprehensive, particularly in relation to referral and medications unavailability.

In conclusion, this study showed that the PMR of HDP was among the highest in the world. The multivariate analysis demonstrated that high parity, low gestational age, lack of antenatal care, having eclampsia, predelivery onset of HDP, raised SGOT level, vaginal delivery, low fetal birth weight, and maternal death were independent predictors of perinatal mortality. The majority of perinatal mortality predictors were also predictors of stillbirths. Since the strong association of perinatal mortality with eclampsia (a late complication of HDP in the majority) [37, 38] and lack of antenatal care is an indirect evidence for the delay in utilization of obstetric services, pregnant women in the study area need to be educated on the importance of antenatal care and HDP symptoms.

\section{Conflict of Interests}

The authors declare that they have no conflict of interests regarding the publication of this paper.

\section{Acknowledgment}

The authors would like to thank UNFPA Ethiopia for the very modest financial support.

\section{References}

[1] National High Blood Pressure Education Program Working Group on High Blood Pressure in Pregnancy, "Report of the national high blood pressure education program working group on high blood pressure in pregnancy," The American Journal of Obstetrics \& Gynecology, vol. 183, no. 1, pp. S1-S22, 2000.

[2] A. R. Vest and L. S. Cho, "Hypertension in pregnancy," Current Atherosclerosis Reports, vol. 16, article 395, 2014.

[3] J. M. Roberts, G. Pearson, J. Cutler, and M. Lindheimer, "Summary of the NHLBI Working Group on research on hypertension during pregnancy," Hypertension, vol. 41, no. 3 I, pp. 437-445, 2003.
[4] C. V. Ananth and O. Basso, "Impact of pregnancy-induced hypertension on stillbirth and neonatal mortality," Epidemiology, vol. 21, no. 1, pp. 118-123, 2010.

[5] E. Abalos, C. Cuesta, G. Carroli et al., "Pre-eclampsia, eclampsia and adverse maternal and perinatal outcomes: a secondary analysis of the World Health Organization Multicountry Survey on Maternal and Newborn Health," British Journal of Obstetrics and Gynaecology, vol. 121, pp. 14-24, 2014.

[6] N. Nusrat, M. Ahson, and A. Munir, "Hypertensive disorders of pregnancy; frequency, maternal and perinatal out comes," Journal of Pakistan Army Medical Corps, vol. 26, no. 1, pp. 119$123,2010$.

[7] G. Yücesoy, S. Ozkan, H. Bodur et al., "Maternal and perinatal outcome in pregnancies complicated with hypertensive disorder of pregnancy: a seven year experience of a tertiary care center," Archives of Gynecology and Obstetrics, vol. 273, no. 1, pp. 43-49, 2005.

[8] S. Teklu and A. Gaym, "Prevalence and clinical correlates of the hypertensive disorders of pregnancy at Tikur Anbessa Hospital, Addis Ababa, Ethiopia," Ethiopian Medical Journal, vol. 44, no. 1, pp. 17-26, 2006.

[9] Z. Wolde, H. Segni, and M. Woldie, "Hypertensive disorders of pregnancy in Jimma University specialized hospital," Ethiopian Journal of Health Sciences, vol. 21, no. 3, pp. 149-152, 2011.

[10] M. Abate and Z. Lakew, "Eclampsia a 5 years retrospective review of 216 cases managed in two teaching hospitals in Addis Ababa," Ethiopian Medical Journal, vol. 44, no. 1, pp. 27-31, 2006.

[11] G. Bayou and Y. Berhan, "Perinatal mortality and associated risk factors: a case control study," Ethiopian Journal of Health Sciences, vol. 22, no. 3, pp. 153-162, 2012.

[12] J. A. Olamijulo and O. O. Olaleye, "Perinatal mortality in Lagos University Teaching Hospital: a five year review," Nigerian Quarterly Journal of Hospital Medicine, vol. 21, no. 4, pp. 255261, 2010.

[13] A. O. Fawole, A. Shah, O. Tongo et al., "Determinants of perinatal mortality in Nigeria," International Journal of Gynecology and Obstetrics, vol. 114, no. 1, pp. 37-42, 2011.

[14] N. T. N. Ngoc, M. Merialdi, H. Abdel-Aleem et al., "Causes of stillbirths and early neonatal deaths: data from 7993 pregnancies in six developing countries," Bulletin of the World Health Organization, vol. 84, no. 9, pp. 699-705, 2006.

[15] R. Sachan, M. L. Patel, P. Sachan, A. Gaurav, M. Singh, and B. Bansal, "Outcomes in hypertensive disorders of pregnancy in the North Indian population," International Journal of Women's Health, vol. 5, no. 1, pp. 101-108, 2013.

[16] B. Bassaw, S. Roopnarinesingh, and A. Sirjusingh, "An audit of perinatal mortality," West Indian Medical Journal, vol. 50, no. 1, pp. 42-46, 2001.

[17] G. A. B. Buga and S. B. Lumu, "Hypertensive disorders of pregnancy at Umtata General Hospital: perinatal and maternal outcomes," East African Medical Journal, vol. 76, no. 4, pp. 217222, 1999.

[18] Y. Berhan and G. Endeshaw, "Maternal mortality predictors in women with hypertensive disorders of pregnancy: a retrospective cohort study in low income country," Ethiopian Journal of Health Sciences, vol. 25, no. 1, pp. 89-98, 2015.

[19] A. Conde-Agudelo and J. M. Belizán, "Risk factors for preeclampsia in a large cohort of Latin American and Caribbean women," British Journal of Obstetrics and Gynaecology, vol. 107, no. 1 , pp. $75-83,2000$. 
[20] S. O. Onuh and A. O. Aisien, "Maternal and fetal outcome in eclamptic patients in Benin City, Nigeria," Journal of Obstetrics and Gynaecology, vol. 24, no. 7, pp. 765-768, 2004.

[21] E. M. Ndaboine, A. Kihunrwa, R. Rumanyika, H. B. Im, and A. N. Massinde, "Maternal and perinatal outcomes among eclamptic patients admitted to Bugando Medical Centre, Mwanza, Tanzania," African Journal of Reproductive Health, vol. 16, no. 1, pp. 35-41, 2012.

[22] V. H. W. Dissanayake, H. D. Samarasinghe, L. Morgan, R. W. Jayasekara, H. R. Seneviratne, and F. B. Pipkin, "Morbidity and mortality associated with pre-eclampsia at two tertiary care hospitals in Sri Lanka," Journal of Obstetrics \& Gynaecology Research, vol. 33, no. 1, pp. 56-62, 2007.

[23] E. D. Adinma, "Maternal and perinatal outcome of eclampsia in tertiary health institution in Southeast Nigeria," Journal of Maternal-Fetal and Neonatal Medicine, vol. 26, no. 2, pp. 211214, 2013.

[24] I. P. Ade-Ojo and O. M. Loto, "Outcome of eclampsiaat the obafemi awolowo university teaching hospital complex, ILEIFE," Nigerian Journal of Clinical Practice, vol. 11, no. 3, pp. 279284, 2008.

[25] J. R. Leiberman, A. Kasis, and I. Shoham-Vardi, "Perinatal mortality in hypertensive disorders in Jewish and Bedouin populations," European Journal of Obstetrics Gynecology and Reproductive Biology, vol. 48, no. 3, pp. 159-167, 1993.

[26] B. S. Aali, J. Ghafoorian, and S. Mohamad-Alizadeh, "Severe preeclampsia and eclampsia in Kerman, Iran: complications and outcomes," Medical Science Monitor, vol. 10, no. 4, pp. CR163-CR167, 2004.

[27] S. G. Gabbe, J. R. Niebyl, and J. L. Simpson, Obstetrics Normal \& Problem Pregnancies, Churchill Livingstone Elsevier, Philadelphia, Pa, USA, 5th edition, 2007.

[28] P. Acién, G. Lloret, and M. Lloret, "Perinatal morbidity and mortality in pregnancy hypertensive disorders: prognostic value of the clinical and laboratory findings," International Journal of Gynecology \& Obstetrics, vol. 32, no. 3, pp. 229-235, 1990.

[29] E. O. V. Ugwu, C. C. Dim, C. D. Okonkw, and T. O. Nwankwo, "Maternal and perinatal outcome of severe pre-eclampsia in Enugu, Nigeria after introduction of Magnesium sulfate," Nigerian Journal of Clinical Practice, vol. 14, no. 4, pp. 418-421, 2011.

[30] J. Tukur, B. Ahonsi, S. Mohammed Ishaku, I. Araoyinbo, E. Okereke, and A. O. Babatunde, "Maternal and fetal outcomes after introduction of magnesium sulphate for treatment of preeclampsia and eclampsia in selected secondary facilities: a low-cost intervention," Maternal and Child Health Journal, vol. 17, no. 7, pp. 1191-1198, 2013.

[31] The Eclampsia Trial Collaborative, "Which anticonvulsant for women with eclampsia? Evidence from the collaborative eclampsia trial," The Lancet, vol. 345, no. 8963, pp. 1455-1463, 1995.

[32] "Do women with pre-eclampsia, and their babies, benefit from magnesium sulphate? The Magpie Trial: a randomised placebocontrolled trial," The Lancet, vol. 359, no. 9321, pp. 1877-1890, 2002.

[33] L. Duley, D. J. Henderson-Smart, G. J. Walker, and D. Chou, "Magnesium sulphate versus diazepam for eclampsia," The Cochrane Database of Systematic Reviews, no. 12, 2010.

[34] K. Adu-Bonsaffoh, O. A. Samuel, G. Binlinla, and O. A. Samuel, "Maternal deaths attributable to hypertensive disorders in a tertiary hospital in Ghana," International Journal of Gynecology and Obstetrics, vol. 123, no. 2, pp. 110-113, 2013.
[35] P. Dasari and S. Habeebullah, "Maternal mortality due to hypertensive disorders of pregnancy in a tertiary care center in Southern India," International Journal of Gynecology \& Obstetrics, vol. 110, no. 3, pp. 271-273, 2010.

[36] J. Moodley, "Maternal deaths associated with hypertensive disorders of pregnancy: a population-based study," Hypertension in Pregnancy, vol. 23, no. 3, pp. 247-256, 2004.

[37] V. L. Katz, R. Farmer, and J. A. Kuller, "Preeclampsia into eclampsia: toward a new paradigm," American Journal of Obstetrics and Gynecology, vol. 182, no. 6, pp. 1389-1396, 2000.

[38] B. M. Sibai, "Diagnosis and management of gestational hypertension and preeclampsia," Obstetrics \& Gynecology, vol. 102, no. 1, pp. 181-192, 2003. 


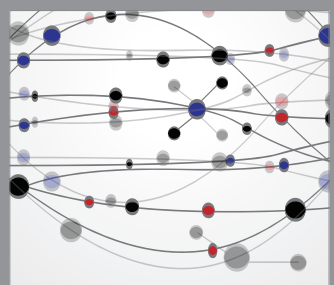

The Scientific World Journal
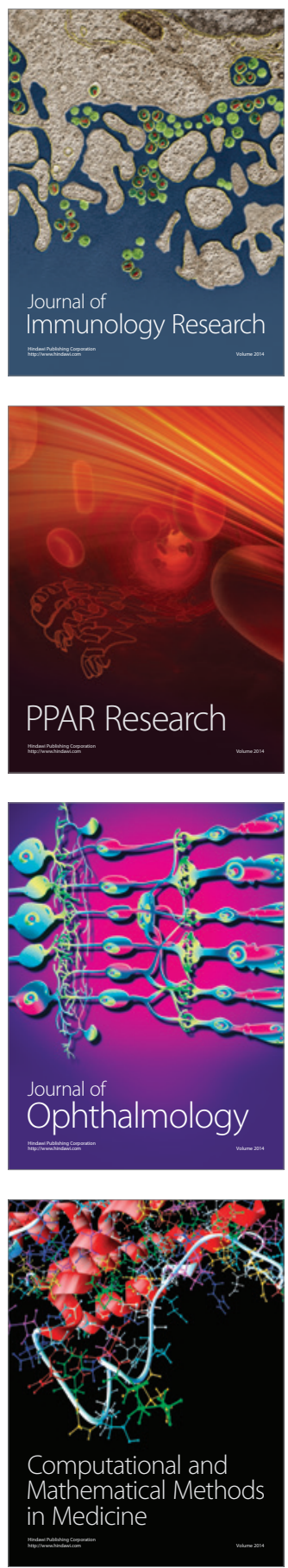

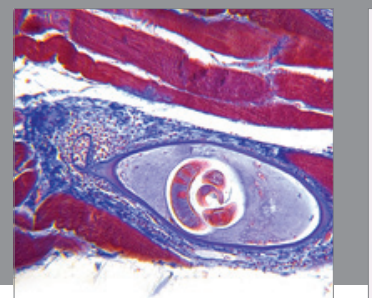

Gastroenterology

Research and Practice
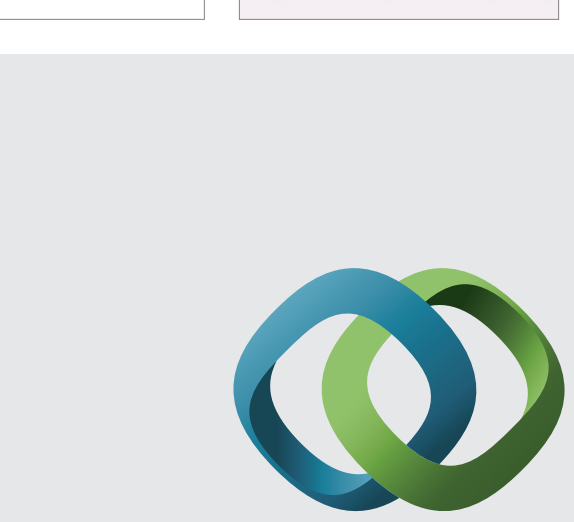

\section{Hindawi}

Submit your manuscripts at

http://www.hindawi.com
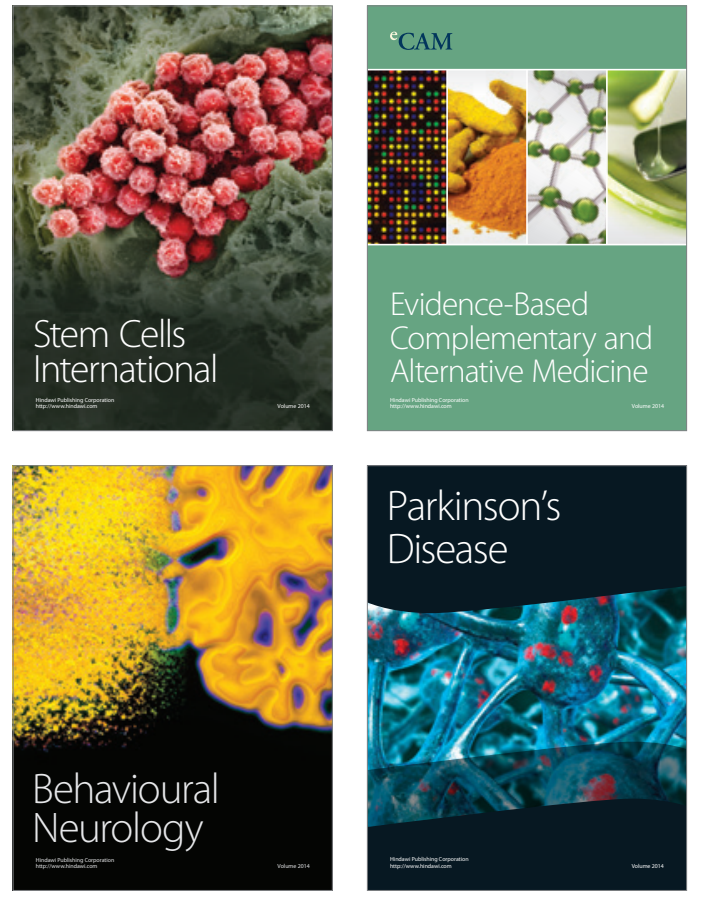
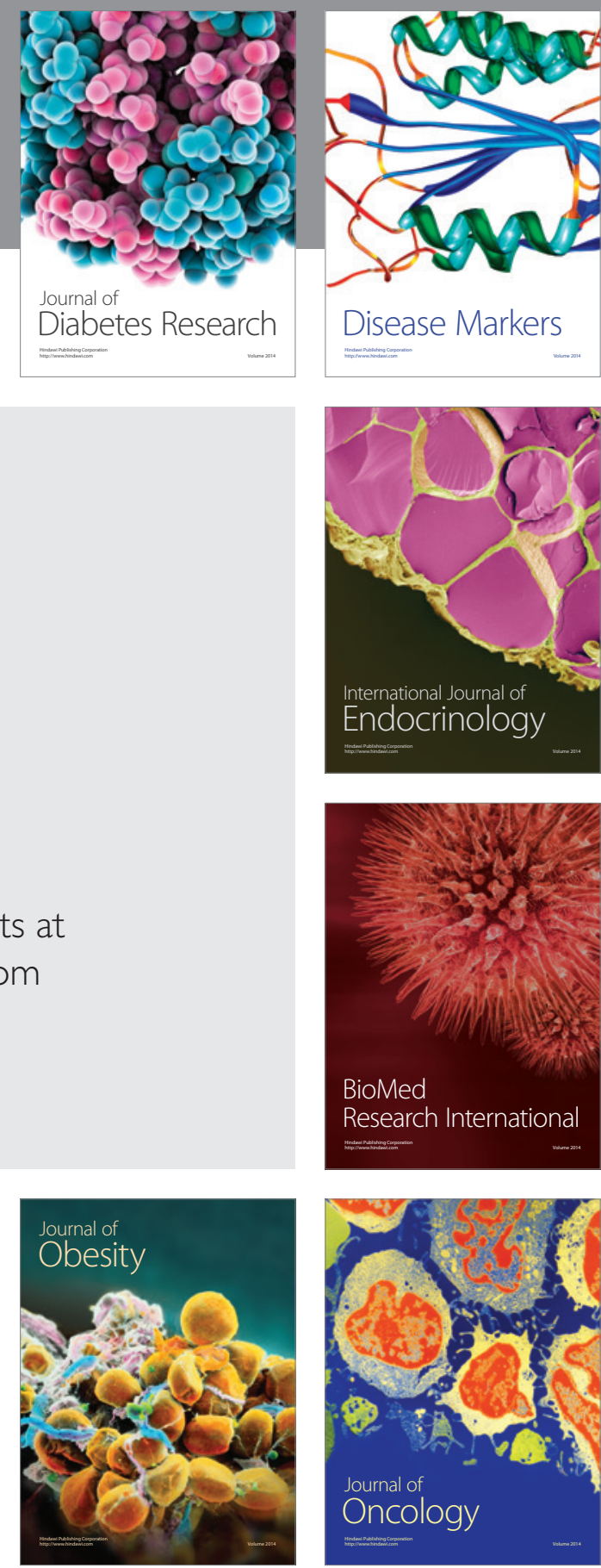

Disease Markers
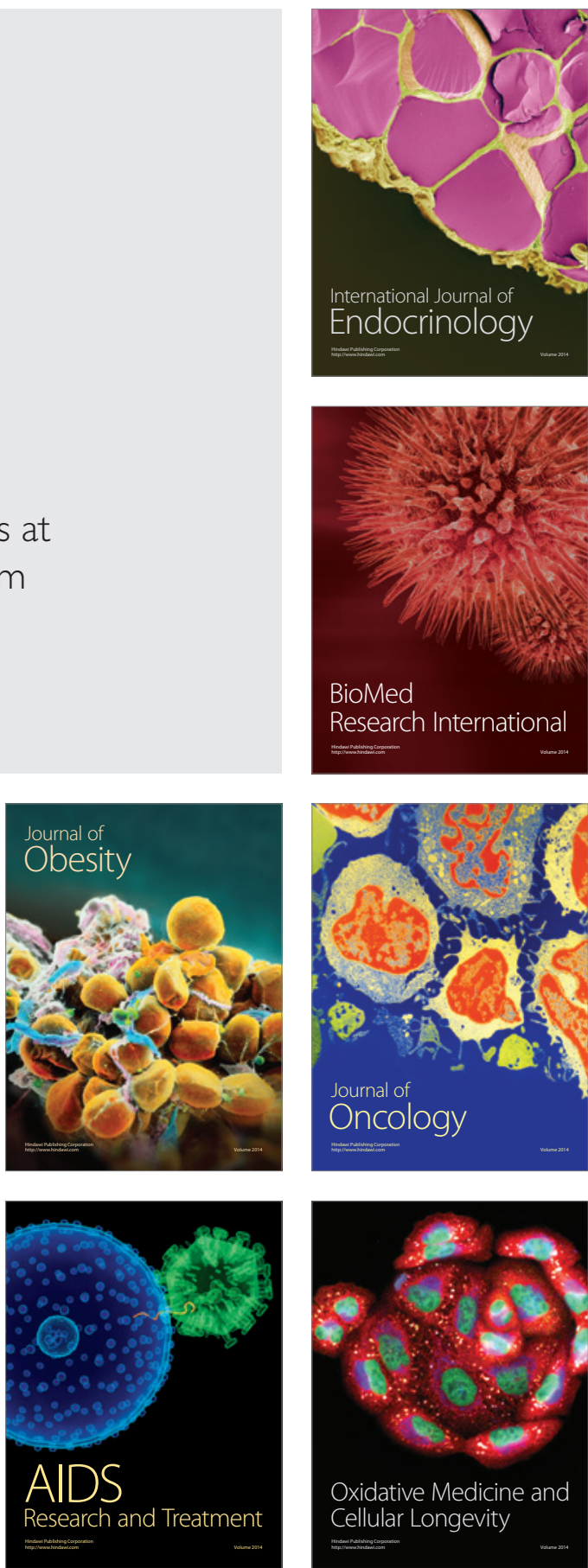